\title{
Human $\mu$-Calpain: Simple Isolation from Erythrocytes and Characterization of Autolysis Fragments
}

\author{
Dusica Gabrijelcic-Geiger ${ }^{1}$, Reinhard Mentele ${ }^{1}$, \\ Barbara Meisel ${ }^{1}$, Heide Hinz ${ }^{1}$, Irmgard \\ Assfalg-Machleidt ${ }^{2}$, Werner Machleidt ${ }^{2}$, \\ Achim Möller ${ }^{3}$ and Ennes A. Auerswald ${ }^{1, a, *}$ \\ ${ }^{1}$ Abteilung für Klinische Chemie und Klinische \\ Biochemie in der Chirurgischen Klinik und Poliklinik- \\ Innenstadt, Klinikum der Ludwig-Maximilians- \\ Universität München, Nußbaumstr. 20, \\ D-80336 München, Germany \\ ${ }^{2}$ Institut für Physiologische Chemie, Physikalische \\ Biochemie und Zellbiologie, Ludwig-Maximilians- \\ Universität München, Goethestr. 33, \\ D-80336 München, Germany \\ ${ }^{3}$ BASF AG, D-67056 Ludwigshafen, Germany \\ ${ }^{*}$ Corresponding author
}

Heterodimeric $\mu$-calpain, consisting of the large (80 $\mathrm{kDa})$ and the small ( $30 \mathrm{kDa})$ subunit, was isolated and purified from human erythrocytes by a highly reproducible four-step purification procedure. Obtained material is more than $95 \%$ pure and has a specific activity of 6-7 mU/mg. Presence of contaminating proteins could not be detected by HPLC and sequence analysis. During storage at $-80{ }^{\circ} \mathrm{C}$ the enzyme remains fully activatable by $\mathrm{Ca}^{2+}$, although the small subunit is partially processed to a $22 \mathrm{kDa}$ fragment. This novel autolysis product of the small subunit starts with the sequence ${ }^{60} \mathrm{RILG}$ and is further processed to the known $18 \mathrm{kDa}$ fragment. Active forms and typical transient and stable autolysis products of the large subunit were identified by protein sequencing. In casein-zymograms only the activatable forms $80 \mathrm{kDa}+30 \mathrm{kDa}, 80 \mathrm{kDa}+22 \mathrm{kDa}$ and $80 \mathrm{kDa}+18$ kDa displayed caseinolysis.

Key words: Autolysis / Calcium activation/Calpain / Cysteine proteases/Purification.

Calpains are intracellular calcium-dependent cysteine proteinases with enzymatic activity at neutral $\mathrm{pH}$. Two ubiquitous types are well characterized, $\mu$ - und $\mathrm{m}$-Calpain (Calpain I and II). These multidomain proteins con-

a Present address: Neurologische Klinik und Poliklinik Großhadern, Klinikum der Universität München, Marchioninistr. 15, D-81377 München, Germany. sist of homologous large, catalytic subunits $(80 \mathrm{kDa})$ and identical small, regulatory subunits (30 kDa) (see Johnson and Guttmann, 1997; Sorimachi et al., 1997; Carafoli and Molinari, 1998; Ono et al. 1999, and for a review Wang et al., 1999). The cDNAs of several isoforms are known (Emori et al., 1986; Sorimachi et al., 1993; GrahamSiegenthaler et al., 1994; Sorimachi et al., 1996; Dear et al., 1997). Calpains have pathophysiological roles in human disorders such as muscle dystrophy, traumatic brain injury, spinal cord injury, cerebral ischemia, myocardial infarction and cataract formation. However, their physiological functions are not yet well understood, and the literature presents a lot of conflicting data on activation, autolysis and protein interactions of calpains (for reviews see Wang and Yuen, 1994; Krampfl et al., 1997; Carafoli and Molinari, 1998; Wang and Yuen, 1999). The calcium-activated proteases were first described in the sixties (Guroff, 1964), purified in the eighties (Yoshimura et al., 1983; Kitahara et al., 1984; Zimmermann and Schlaepfer, 1984; Crawford et al., 1987) and isolated by improved affinity chromatography in the nineties (Molinari et al., 1995; Anagli et al., 1996). But even today isolation of $\mu$-calpain is a difficult task (Croall, 2000; Thompson and Goll, 2000). Frequently, SDS polyacrylamide gel electrophoresis reveals more bands than the expected $80 \mathrm{kDa}$ and $30 \mathrm{kDa}$ forms. Here, we describe an optimized isolation procedure for $\mu$-calpain from human erythrocytes which yields a pure, highly active and relatively stable enzyme.

Purification of human $\mu$-calpain was performed at $4{ }^{\circ} \mathrm{C}$. Erythrocyte concentrate $(600 \mathrm{ml}$ corresponding to 1 liter of whole blood) was washed twice with washing solution (0.15 M NaCl, $2 \mathrm{mM}$ EDTA, pH 7.5) and centrifuged $(1000 \mathrm{~g})$, lysed for $15 \mathrm{~min}$ at room temperature with lysing buffer (15 mM Tris-HCl, 2 mm EDTA, pH 7.5, 0.5 mm Pefabloc) and centrifuged again (1 h, $20000 \mathrm{~g})$. The supernatant was diluted 1:1 (v/v) with buffer A (20 mM Tris/HCl, 2 mM EDTA, pH 7.5) and applied to an equilibrated DEAESepharose column (Pharmacia XK 50/30). The column was washed with buffer $A$ until $E_{280}<0.010$ and equilibrated with a mixture of $87: 13$ parts $(\mathrm{v} / \mathrm{v})$ of buffer $A$ and buffer B (20 mM Tris/HCl, 2 mM EDTA, pH 7.5, 0.5 M NaCl). Calpain/calpastatin complexes were eluted with buffer $\mathrm{B}$, adjusted to $1.2 \mathrm{M} \mathrm{NaCl}$ and applied to a PhenylSepharose column (Pharmacia XK 50/20) equilibrated with $1.2 \mathrm{M} \mathrm{NaCl}$ in buffer $\mathrm{C}(20 \mathrm{~mm}$ Tris/ $\mathrm{HCl}, 2 \mathrm{~mm}$ EDTA, $\mathrm{pH}$ 7.3). Elution of $\mu$-calpain was performed by a descending linear gradient from 1.2 to $0 \mathrm{M} \mathrm{NaCl}$ in buffer $\mathrm{C}$. 
Active fractions were collected (positive in the caseinCoomassie test; Buroker-Kilgore and Wang, 1993), concentrated by ultrafiltration to $10 \mathrm{ml}$ (Amicon $10 \mathrm{kDa}$ cutoff membrane) and further purified on Superdex 200 (Pharmacia 100/3) equilibrated with $0.4 \mathrm{M} \mathrm{NaCl}$ in buffer C. The eluted active fractions were applied to a BlueSepharose column (Pharmacia Blue Sepharose Hi Trap 5 $\mathrm{ml}$ prepacked), washed with $0.25 \mathrm{M} \mathrm{NaCl}$ in buffer $\mathrm{C}$ and eluted by a stepwise gradient from 0.25 to $0 \mathrm{M} \mathrm{NaCl}$ in buffer $\mathrm{C}$. Finally, isolated $\mu$-calpain was concentrated and stored in aliquots $(1-2 \mathrm{mg} / \mathrm{ml})$.

We routinely obtained approx. 1.5 to $2 \mathrm{mg}$ of highly purified $\mu$-calpain from $600 \mathrm{ml}$ of human erythrocyte concentrate. The isolation procedure includes 4 main steps: ion exchange chromatography, hydrophobic interaction chromatography, gel filtration and affinity chromatography in a very reproducible manner. In fresh preparations two single protein bands were obtained after SDS-PAGE (Laemmli, 1970) corresponding to apparent molecular masses of $80 \mathrm{kDa}$ and $30 \mathrm{kDa}$ (Figure 1). These two bands were primarily identified by anti-domain II and anti-30 kDA monoclonal antibodies as the large and small subunit of $\mu$-calpain (data not shown). Direct Edman degradation of eluted bands failed because the $\mathrm{N}$ termini of both subunits are blocked, but endoproteinase Lys-C cleavage, peptide mapping and partial peptide sequencing of two selected peptides yielded internal sequences of the corresponding subunits.

Fresh material was analyzed by reversed-phase HPLC (Figure 2). Three fractions were separated: the latest eluting fraction $\mathrm{C}$ consists of pure heterodimeric $\mu$-calpain ( $80 \mathrm{kDA}$ und $30 \mathrm{kDA}$ ); its composition was determined by endoproteinase Lys-C cleavage, peptide mapping and protein sequencing $\left({ }^{21} \mathrm{Q}-\mathrm{R}-\mathrm{A}-\mathrm{R}-\mathrm{E}-\mathrm{L}-\mathrm{G}-\right.$ for the $80 \mathrm{kDa}-$ form and ${ }^{126} \mathrm{~V}-\mathrm{V}-\mathrm{T}-\mathrm{R}-\mathrm{H}$ - for the $30 \mathrm{kDa}$-form). Fraction $\mathrm{B}$ (about $20 \%$ by weight of total) consists of pure homogeneous $30 \mathrm{kDa}$ subunit ( $\left.{ }^{164} \mathrm{R}-\mathrm{W}-\mathrm{Q}-\mathrm{A}-\mathrm{I}-\mathrm{Y}-\right)$. The small frac-

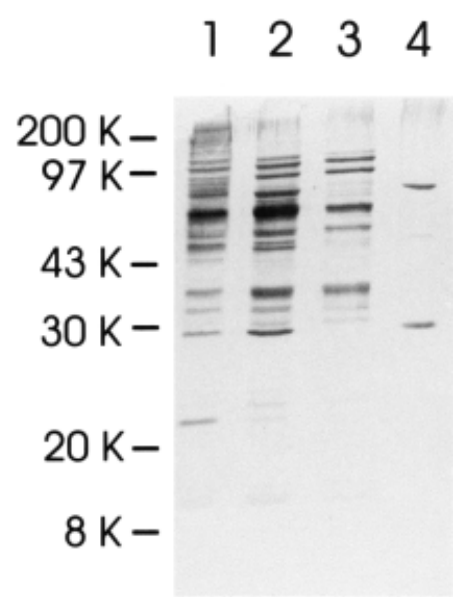

Fig. 1 SDS-PAGE Documenting the Purification of $\mu$-Calpain. Lane 1, $\mu$-calpain fraction obtained after phenyl-Sepharose; lane $2, \mu$-calpain fraction after gel filtration; lane 3 , material not retained by the Blue-Sepharose column; lane 4 , purified $\mu$-calpain obtained after Blue-Sepharose chromatography.

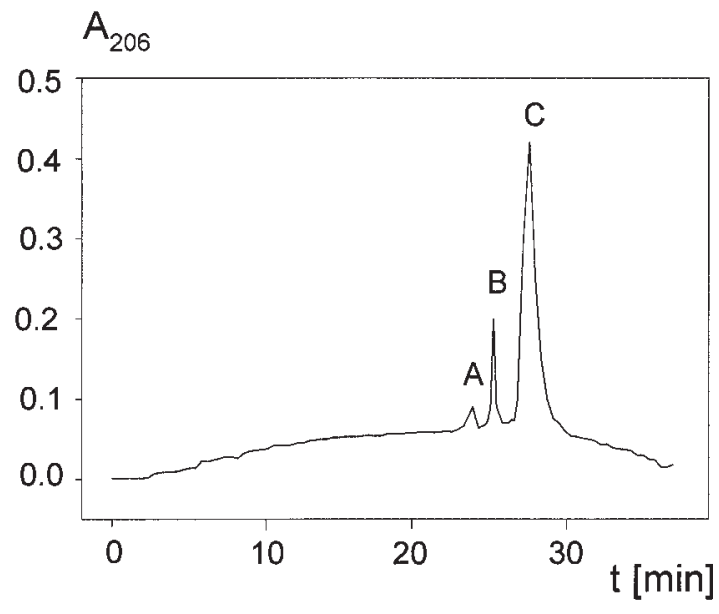

Fig. 2 Separation of Freshly Purified $\mu$-Calpain by HPLC. Purified calpain $(20 \mu \mathrm{g})$ was analyzed by reversed-phase HPLC with Aquapore RP 300 (Applied Biosystems GmbH, Weiterstadt, Germany) and a linear gradient of $0-80 \%(\mathrm{v} / \mathrm{v})$ acetonitrile in $0.1 \%(\mathrm{v} / \mathrm{v})$ trifluoroacetic acid and $30 \%(\mathrm{v} / \mathrm{v})$ isopropanol at a flow rate of $1 \mathrm{ml} / \mathrm{min}$. Absorption was recorded at $206 \mathrm{~nm}$. Samples were analyzed by SDS-PAGE and sequenced after transfer to PVDF membranes using a gas-phase sequenator 473A (Applied Biosystems $\mathrm{GmbH}$ ) according the instructions of the manufacturer.

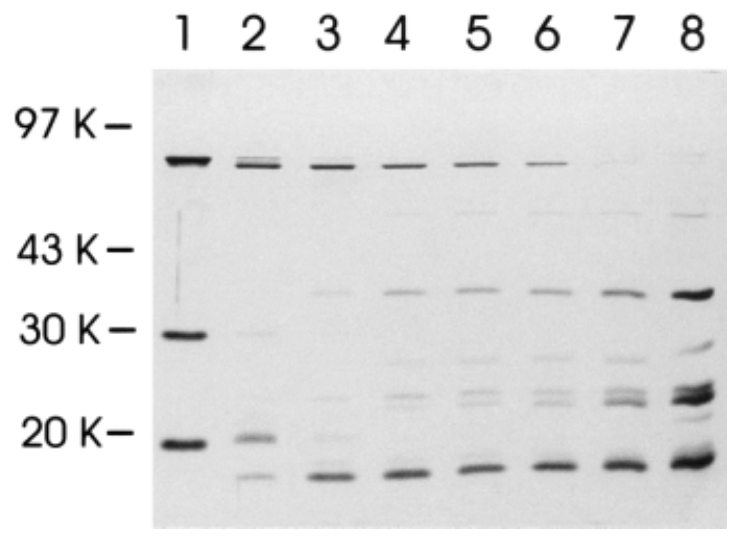

Fig. 3 In vitro Autolysis of Human $\mu$-Calpain Followed by SDSPAGE.

Lane 1, purified $\mu$-calpain after storage for 2 weeks at $-80{ }^{\circ} \mathrm{C}$; lanes 2-8, autolytic fragments $0 \mathrm{~min}(2), 1 \mathrm{~min}(3), 5 \mathrm{~min}$ (4), 15 $\min (5), 30 \mathrm{~min}(6), 60 \mathrm{~min}(7)$ and $120 \mathrm{~min}(8)$ after addition of 0.5 $\mathrm{mm}$ free $\mathrm{Ca}^{2+}$ (final concentration) to purified $\mu$-calpain $(27.5 \mu \mathrm{g})$ in $50 \mathrm{~mm}$ Tris- $\mathrm{HCl}, \mathrm{pH} 7.5,100 \mathrm{~mm} \mathrm{NaCl}$ and $1 \mathrm{~mm}$ DTT at room temperature. After the indicated time intervals aliquots were taken $(1.1 \mu \mathrm{g})$, EDTA was added ( $25 \mathrm{~mm}$ final concentration) and the material was applied to the gel.

tion A (about $20 \%$ by weight of total) is a mixture of three heterogenously cleaved $30 \mathrm{kDa}$-forms, (-M-R-I-) $\downarrow^{62} \mathrm{~L}-\mathrm{G}-$ G-V-I-S-, (-G-V-I-) $\downarrow^{68}$ S-A-I-S-E-A-A- and (-S-A-I-) $\downarrow^{71}$ SE-A-A-A-Q-. These three minor fractions represent 'autolysed' fragments that have not been described so far.

Unexpectedly, the purified calpain shows a new prominent band at $22 \mathrm{kDA}$ in SDS-PAGE after short storage at $4{ }^{\circ} \mathrm{C}$ and after longer storage at $-80{ }^{\circ} \mathrm{C}$ (Figure 3), al- 


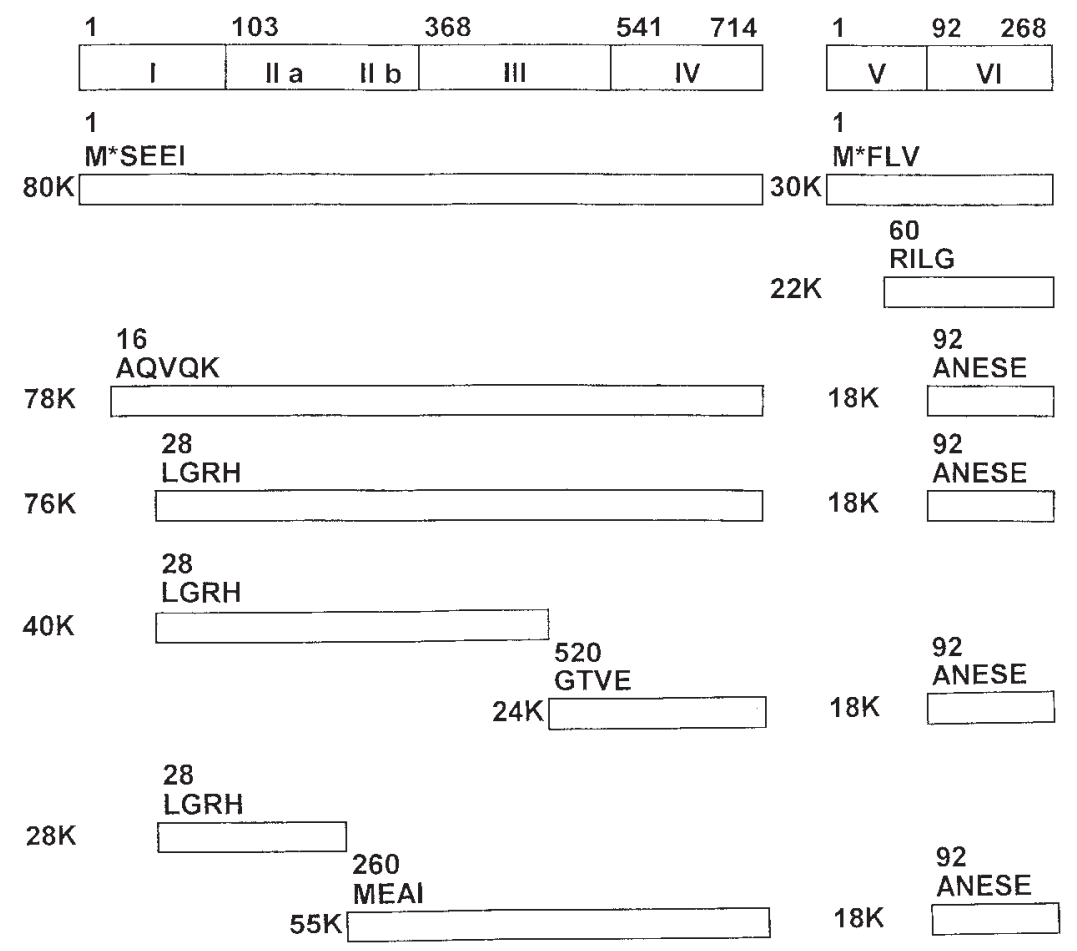

Fig. 4 Scheme of Observed Autolysis Fragments of Purified $\mu$-Calpain after Calcium Activation. Cleavage points are identified by their $\mathrm{N}$-terminal sequences.

though the material was kept in 2 mM EDTA. The N-terminal sequence of the $22 \mathrm{kDa}$ fragment, ${ }^{60} \mathrm{R}-\mathrm{I}-\mathrm{L}-\mathrm{E}-$-, is located in domain $\mathrm{V} 26$ or 32 amino acids upstream of the well-known $21 \mathrm{kDa}\left({ }^{86} \mathrm{H}-\mathrm{Y}-\mathrm{S}-\mathrm{N}-\mathrm{I}-\mathrm{E}-\right)$ or $18 \mathrm{kDa}\left({ }^{92} \mathrm{~A}-\mathrm{N}-\mathrm{E}-\right.$ $\mathrm{S}-\mathrm{E}-$ ) autolysis products of the $30 \mathrm{kDa}$ form (Emori et al., 1986; McClelland et al., 1989; Nishimura and Goll, 1991; Figure 4). The cleavage leading to this novel fragment may be due to (i) an undetected contaminating protease, or (ii) to a minor 'dormant' activity of purified $\mu$-calpain itself. It can be hypothesized further that the cleavage site may be located close to the broad active-site cleft of calpain (Hosfield et al., 1999; Strobl et al., 2000). A comparable $23 \mathrm{kDa}$ autolysis product of the small subunit ( ${ }^{64} \mathrm{G}-\mathrm{V}-\mathrm{I}-\mathrm{S}-\mathrm{A}-$, starting 4 amino acid residues upstream of $\left.{ }^{60} \mathrm{R}-\mathrm{I}-\mathrm{L}-\mathrm{G}-\mathrm{A}-\mathrm{Q}-\right)$ was described by McClelland and coworkers after $\mathrm{Ca}^{2+}$-activation (McClelland et al., 1989). Heterogeneity of EDTA-stored $\mu$-calpain, due to the formation of the $22 \mathrm{kDa}$ fragment, may explain the fact that extended crystallization experiments with our purified enzyme were not successful (W. Bode, personal communication). Figure 4 summarizes the complex pattern of transient ( $80 \mathrm{kDa}, 78 \mathrm{kDa}, 76 \mathrm{kDa}, 55 \mathrm{kDa}, 30 \mathrm{kDa}, 21$ $\mathrm{kDa}$ ) and stable (40 kDa, $28 \mathrm{kDa}, 24 \mathrm{kDa}, 18 \mathrm{kDa}$ ) autolysis products of our purified $\mu$-calpain.

Enzymatic activity of $\mu$-calpain was measured in 'continuous' fluorimetric assays using Suc-Leu-Tyr-NH-Mec $(250 \mu \mathrm{M})$ as substrate at $12{ }^{\circ} \mathrm{C}, \mathrm{pH} 7.5$, with $200 \mu \mathrm{M} \mathrm{CaCl}{ }_{2}$ as described in detail previously (Garcia-Diaz et al., 2001). The purified enzyme had a specific activity between 5 and $7 \mathrm{mU} / \mathrm{mg}$ under the conditions given above. After extrapolation to saturating substrate concentra- tions, this value $(123 \mathrm{mU} / \mathrm{mg})$ corresponds well to the specific activity of porcine calpain $(76.3 \mathrm{mU} / \mathrm{mg})$ reported by Sasaki et al. (1984).

Fresh and stored purified calpains were analyzed by casein zymography before and after activation using non-denaturing gel electrophoresis (Raser et al., 1995). As little as $10 \mathrm{ng}$ fresh $\mu$-calpain ( $80 \mathrm{kDa}$ and $30 \mathrm{kDa}$ ) was detected as a single band. If $5 \mu \mathrm{g}$ were applied, two additional quicker migrating tiny bands could be detected (Figure 5; line $\mu \#$ ). With stored $\mu$-calpain we found two strong caseinolytic activities which represent the 80

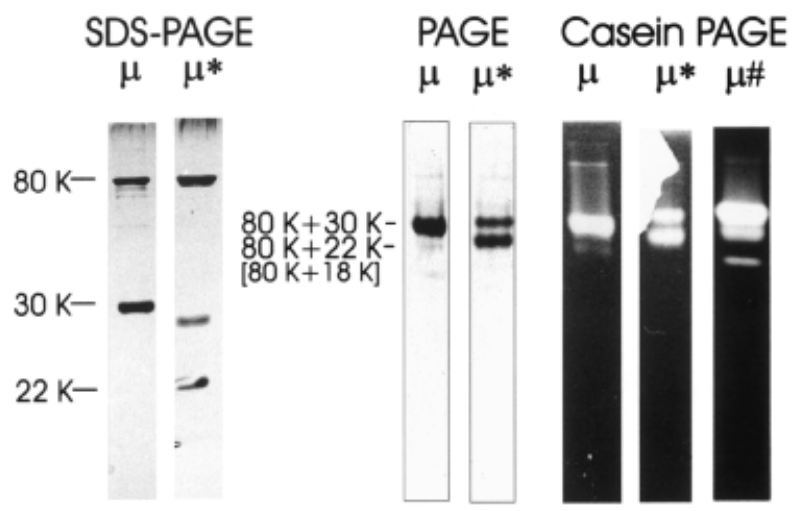

Fig. 5 Comparison of Purified $\mu$-Calpain from Human Erythrocytes in SDS-PAGE, Native PAGE and PAGE Containing Casein (Casein-PAGE).

$\mu$, purified $\mu$-calpain $(1 \mu \mathrm{g})$ immediately after isolation; $\mu^{*}$, purified $\mu$-calpain $(1 \mu \mathrm{g})$ after storage for 2 weeks at $-80^{\circ} \mathrm{C} ; \mu \#$, purified $\mu$-calpain $(5 \mu \mathrm{g})$ immediately after isolation. 
$\mathrm{kDa}+30 \mathrm{kDa}$ and $80 \mathrm{kDa}+21 \mathrm{kDa}$ forms (Figure 5; line $\mu^{*}$ ). No caseinolytic activity was found when already activated $\mu$-calpain forms (78 kDa+18 kDa, 76 kDa+, 18 kDa) were applied to the zymograms (data not shown). This may be explained by further autolysis of the activated forms during electrophoresis leading to inactivation. All caseinolytic bands were completely inhibited by the recombinant calpastatin domain I and by the inhibitor ZLLY-CHN ${ }_{2}$.

\section{Acknowledgements}

The authors thank Bernd Gerhartz, Halle, Milton Stubbs, Marburg and John Elce, Kingston, Ontario, Canada, for encouragement and stimulating discussion. Protein sequencing work was performed in the laboratories of Prof. F. Lottspeich, Martinsried, Germany. We would like to thank Prof. H. Fritz for support and stimulating comments. This work was supported by the Sonderforschungsbereich 469, Ludwig-Maximilians-Universität München, Germany (grants A-6 Machleidt, A-3 Auerswald) and the BASF AG, Ludwigshafen, Germany.

\section{References}

Anagli, J., Vilei, E. M., Molinari, M., Calderara, S. and Carafoli, E. (1996). Purification of active calpain by affinity chromatography on an immobilized peptide inhibitor. Eur. J. Biochem. 241 , 948-954.

Buroker-Kilgore, M., and Wang, K. W. (1993). A Coomassie Brilliant Blue G-250-based colorimetric assay for measuring activity of calpain and other proteinases. Anal. Biochem. 208, 387-392.

Carafoli, E., and Molinari, M. (1998). Calpain: a protease in search of a function? Biochem. Biophys. Res. Commun. 247 193-203.

Crawford, C. (1987). Inhibition of chicken calpain II by proteins of the cystatin superfamily and $\alpha_{2}$-Macroglobulin. Biochem. J. $248,589-594$

Croall, D. E. (2000). Purification of calpain by affinity chromatography on reactive red-agarose or on casein-sepharose. Methods Mol. Biol. 144, 33-40.

Dear, N., Matena, K., Vingron, M., and Boehm T. (1997). A new subfamily of vertebrate calpains lacking a calmodulin-like domain: implications for calpain regulation and evolution. Genomics 45, 175-184.

Emori, Y., Ohno, S., Tobita, M., and Suzuki, K. (1986). Gene structure of calcium-dependent protease retains the ancestral organization of the calcium-binding protein. FEBS Lett. 194 $249-252$.

Garcia-Diaz, B., Gross, S., Assfalg-Machleidt, I., Pfeiler, D., Gollmitzer, N., Gabrijelcic-Geiger, D., Stubbs, M.T., Fritz, H., Auerswald E.A., and Machleidt, W. (2001). Cystatins as calpain inhibitors: engineered chicken cystatin- and stefin Bkininogen domain 2 hybrids suppport a cystatin-like mode of interaction with the catalytic subunit of $\mu$-calpain. Biol. Chem. $382,97-102$.

Graham-Siegenthaler, K., Gauthier, S., Davies, P.L., and Elce, J.S. (1994). Active recombinant rat calpain II: bacterially produced large and small subunits associate both in vivo and in vitro. J. Biol. Chem. 269, 30457-30460.

Guroff, G. (1964). A neutral, calcium-activated proteinase from the soluble fraction of rat brain. J. Biol. Chem. 239, 149-155.
Hosfield, C.M., Elce, J.S., Davies, P.L., and Jia, Z. (1999). Crystal structure of calpain reveals the structural basis for $\mathrm{Ca}^{2+}-\mathrm{de}-$ pendent protease activity and a novel mode of enzyme activation. EMBO J. 18, 6880-6889.

Johnson, G.V.W., and Guttmann, R.P. (1997). Calpains: intact and active? Bioessays 19, 1011-1018.

Kampfl, A., Posmantur, R.M., Zhao, X., Schmutzhard, E., Clifton, G.L., and Hayes, R.L. (1997). Mechanisms of calpain proteolysis following traumatic brain injury: implications for pathology and therapy: a review and update. J. Neurotrauma 14 , $121-134$.

Kitahara, A., Sasaki, T., Kikuchi, T., Yumoto, N., Yoshimura, N., Hatanaka, M., and Murachi, T. (1984). Large-scale purification of porcine calpain I and calpain II and comparison of proteolytic fragments of their subunits. J. Biochem. 95, $1759-1766$.

Laemmli, U.K. (1970). Cleavage of structural proteins during the assembly of the head of the bacteriophage T4. Nature 227, 680-685.

McClelland, P., Lash, J.A., and Hathaway, D.R. (1989). Identification of major autolytic cleavage sites in the regulatory subunit of vascular calpain II. A comparison of partial amino-terminal sequences to deduced sequence from complementary DNA. J. Biol. Chem. 264, 17428-17431.

Molinari, M., Maki, M., and Carafoli, E. (1995). Purification of mu.calpain by a novel affinity chromatography approach: new insights into the mechanism of the interaction of the protease with targets. J. Biol. Chem. 270, 14576-14581.

Nishimura, T., and Goll, D. E. (1991). Binding of calpain fragments to calpastatin. J. Biol. Chem. 266, 11842-11850.

Ono, Y., Sorimachi, H., and Suzuki, K. (1999). The calpain superfamily. 1-23. In: Calpain: Pharmacology and Toxicology of Calcium-Dependent Protease, K.K.W. Wang and P-W. Yuen, eds. (Philadelphia, USA: Taylor and Francis).

Raser, K.J., Posner, A., and Wang, K.K.W. (1995). Casein zymography: a method to study $\mu$-calpain, $m$-calpain, and their inhibitory agents. Arch. Biochem. Biophys. 319, 211-216.

Sasaki, T., Kikuchi, T., Yumoto, N., Yoshimura, N., and Murachi, T. (1984). Comparative specificity and kinetic studies on porcine calpain I and calpain II with naturally occuring peptides and synthetic fluorogenic substrates. J. Biol. Chem. 259, $12489-12494$.

Sorimachi, H., Toyama-Sorimachi, N., Saido, T.C., Kawasaki, H., Sugita, H., Miyasaka, M., Arahata, K-i., Isihura, S., and Suzu$\mathrm{ki}, \mathrm{K}$. (1993). Muscle specific calpain, p94, is degraded by autolysis immediately after translation, resulting in disappearance from muscle. J. Biol. Chem. 268, 10593-10605.

Sorimachi, H., Amano, S., Ishiura, S., and Suzuki, K. (1996). Primary sequence of rat $\mu$-calpain large and small subunits are respectively, moderately and highly similar to those of human. Biochim. Biophys. Acta 1309, 37-41.

Sorimachi, H., Ishiura, S., and Suzuki, K. (1997). Structure and physiological function of calpains. Biochem. J. 328, 721-732.

Strobl, S. Fernandez-Catalan, C., Braun, M., Huber, R., Masumoto, H., Nakagawa, K., Irie, A., Sorimachi, H., Bourenkow, G., Bartunik, H., Suzuki, K., and Bode, W. (2000). The crystal structure of calcium-free human $\mathrm{m}$-calpain suggests an electrostatic switch mechanism for activation by calcium. Proc. Natl. Acad. Sci. USA 97, 588-592.

Thompson, V.F., and Goll, D.E. (2000). Purification of $\mu$-calpain, $\mathrm{m}$-calpain, and calpastatin from animal tissues. Methods Mol. Biol. 144, 3-16.

Wang, K.K.W., and Yuen, P.W. (1994). Calpain inhibition: an overview of its therapeutic potential. Trends Pharmacol. Sci. $15,412-419$.

Wang, K. K. W., and Yuen, P. W., eds. (1999). Calpain: Pharma- 
cology and Toxikology of Calcium-Dependent Protease (Philadelphia, USA: Taylor and Francis).

Yoshimura, N., Kikuchi, T., Sasaki, T., Kitahara, A., Hatanaka, M. and Murachi, T. (1983). Two distinct $\mathrm{Ca}^{2+}$ proteases (calpain I and calpain II) purified concurrently by the same method from rat kidney. J. Biol. Chem. 258, 8883-8889.
Zimmermann, U.J.P., and Schlaepfer, W.W. (1984). Multiple forms of Ca-activated protease from rat brain and muscle. J. Biol. Chem. 259, 3210-3218.

Received August 27, 2001; accepted October 24, 2001 